\title{
Desafios na Produção do Cuidado em um Centro de Atenção Psicossocial Álcool e Drogas
}

Challenge in the Production of Care in a Center for Psychosocial Care and Drugs

Desafío en la Producción de la Atención en un Centro de Atención Psicosocial Alcohol y Drogas

Kallen Dettmann Wandekoken ${ }^{1}$; Maristela Dalbello-Araujo ${ }^{2}$; Luiz Henrique Borges ${ }^{3}$.

\section{Resumo}

Este artigo analisa os desafios de produção do cuidado em um Centro de Atenção Psicossocial Álcool e Drogas (CAPSad), em busca de agir consonante às políticas que orientam este serviço. Debruça-se, também, em analisar as dimensões macro e micropolíticas que permeiam esta prática e elucida estratégias do processo de trabalho que são vivenciadas pelos trabalhadores. Assim, foi realizada pesquisa qualitativa

\footnotetext{
${ }^{1}$ Doutora em Saúde Coletiva pela Universidade Federal do Espírito Santo. Prof ${ }^{a}$. Adjunta do Departamento de Enfermagem da Universidade Federal do Espírito Santo. Endereço: Av. Gil Veloso, n. 1000, Praia da Costa, Vila Velha-ES, Brasil. CEP: 29101010. E-mail: kallendw@gmail.com.

2 Doutora em Psicologia pela Universidade Federal do Espírito Santo. Prof ${ }^{a}$. do Programa de Pós-graduação em Pólíticas Públicas da Escola Superior de Ciências da Santa Casa de Misericórdia de Vitória. E-mail: dalbello.araujo@gmail.com.

${ }^{3}$ Doutorado em Ciências da Saúde pela Universidade Federal do Rio de Janeiro. Prof. Adjunto da Escola Superior de Ciências da Santa Casa de Misericórdia de Vitória. E-mail: luiz.borges@emescam.br.
}

com todos os 28 trabalhadores do serviço, a partir de oitenta horas de observação do cotidiano de trabalho, uma sessão de entrevista coletiva, com a participação de dez trabalhadores e treze entrevistas em profundidade individuais, seguidas de Análise Temática. Logo, considerando que a produção do cuidado em saúde se dá sempre em relação, constata-se que neste serviço há comprometimento de sua efetividade. Foram observados três modos de cuidar: 1. Cuidado centrado no ato prescritivo; 2. Cuidado pouco relacional; 3 . Cuidado acolhedor. Para tanto, entende-se que produzir atos de saúde a partir de um cuidado acolhedor é tarefa de todos os profissionais do CAPSad e que estes devem reconhecer, no usuário, um sujeito portador de desejos e necessidades, que possui valores e potências. Entretanto, nas condições em que o trabalho é realizado, nesse local, o cuidado parece comprometido. 
Descritores: Centros de Atenção Psicossocial. Trabalho. Atenção Integral à Saúde.

\section{Abstract}

This article analyzes the challenges of producing care in a Psychosocial Care Center for Alcohol and Drugs (CAPSad), seeking to act in consonance with the policies that guide this service. It also focuses on analyzing the macro and micropolitical dimensions that permeate this practice and elucidates strategies of the work process that are experienced by the workers. Thus, a qualitative research was carried out with all 28 employees of the service. Eighty hours of observation of daily work were done, a collective interview session with the participation of ten workers and thirteen individual in-depth interviews followed by Thematic Analysis. Therefore, considering that the production of health care is always in relation, we find that in this service there is compromise of its effectiveness. We point out three modes of care observed: 1. Care centered on the prescriptive act; 2. Careful little relational; 3. Warm care. Therefore, we understand that to produce health care from a warm care is the task of all the professionals of CAPSad and that they must recognize in the user a subject who has desires and needs, who has values and powers. However, under the conditions in which work is performed at this location, care seems compromised.

Descritores Inglês: Mental Health Services. Work. Comprehensive Health Care.

\section{Resumen}

Este artículo analiza los retos de producción atención en un Centro de Atención Psicosocial Alcohol y Drogas (CAPSad), tratando de actuar de acuerdo con las políticas que guían este servicio. También se centra en el análisis de las dimensiones de macro y micropolítica que impregnan esta práctica y estrategias aclara el proceso de trabajo que son experimentados por los trabajadores. Así, se realizó una investigación cualitativa con los 28 empleados del servicio. Se realizaron ochenta horas de observación del trabajo diario, una sesión de conferencia de prensa con la participación de diez trabajadores y trece entrevistas individuales siguió la profundidad del análisis temático. Luego, considerando que la producción de la asistencia sanitaria siempre se hace cargo, nos encontramos con que este servicio se ve comprometida su eficacia. Señalamos tres modalidades de atención observados: 1. La atención se centró en acto prescriptivo; 2. La atención 
relacional pequeño; 3. Cuidado de bienvenida. Para tanto, entendemos que la producción de las acciones de salud a partir de una acogedora atención es una tarea para todos los profesionales CAPSad y que deben reconocer al usuario un portador sujeto deseos $\mathrm{y}$ necesidades, que tiene valores y poderes. Sin embargo, las condiciones en las que el trabajo se lleva a cabo allí, la atención parece comprometida.

Descritores Espanhol: Servicios de Salud Mental. Trabajo. Atención Integral de Salud.

\section{Introdução}

A partir da constatação de que o trabalho em saúde se realiza por meio das relações, de embates entre necessidades e interesses, Franco et al (2011) mencionam que, para se compreender a micropolítica* do processo de trabalho em saúde, é preciso entender o modo como se produz o cuidado no serviço, considerando as interfaces de saberes e poderes, as intersubjetividades e, ainda, desvendando aspectos do encontro entre os trabalhadores e os usuários.

Assim, é no território de ações cuidadoras que há a produção do encontro e a possibilidade de construções afetivas. Por isso, o cuidado é a alma dos serviços de saúde e a estratégia radical para defesa da vida (Merhy; Feuerwerker; Cerqueira, 2014). Nesse sentido, é importante destacar o que se entende por produção de cuidado. Compreende-se que as ações cuidadoras não são de domínio apenas dos trabalhadores da saúde (médicos, enfermeiros, etc.), pois se trata de domínio de todos que, de alguma forma, atuam na área da saúde (seja o vigia, o auxiliar de serviços, o recepcionista, etc.), além dos próprios usuários e seus familiares. Ou seja, a produção de cuidado deve ser compartilhada por todos, uma vez que a todos são válidos os atos de acolhimento, de escuta, o mostrar-se interessado, de forma a possibilitar o encontro que seja de conforto, a partir dos olhares diferenciados (Merhy; Feuerwerker; Cerqueira, 2014). Essas questões implicam colocar o usuário em uma posição de sujeito ativo do seu processo saúde-doença, o que, de fato, é bem diferente do modelo de assistência hegemônico que o mantém como objeto das ações de saúde (Merhy; Feuerwerker; Cerqueira, 2010).

Ao estudar sobre os modelos de atenção, Merhy (1998) destaca que há três dimensões tecnológicas para a produção do cuidado que irão interferir de formas diferenciadas nesse processo, dependendo de diversos fatores: 
tecnologias duras, leve-duras e leves. As tecnologias duras se referem a equipamentos, instrumentos e outros materiais usados em diagnósticos e tratamentos; as leve-duras são os conhecimentos estruturados dos diversos saberes presentes nas práticas de saúde; e as tecnologias leves, que se referem às relações construídas entre duas pessoas em ato, produzindo uma relação de vínculo e aceitação, determinantes para a ação criadora de novos padrões assistenciais (Merhy, 2007).

* Deleuze e Guattari (1996) esclarecem que a macropolítica tem a ver com a organização e funcionamento das instituições; já a micropolítica diz respeito aos fluxos e processos, ou seja, aos sujeitos e suas relações.

Neste contexto, Merhy, Feuerwerker e Cerqueira (2014) explicam que a atividade clínica é território das tecnologias leves-duras, de forma que as negociações estabelecidas no encontro se referem à subordinação dos usuários frente aos detentores do saber. Já a partir das tecnologias leves, os saberes são apresentados como oferta e não como imposição de um estilo de vida. "Podem ser ferramentas para lidar com a diferença na produção da vida e não como uma carapaça que nos aprisiona na repetição" (Merhy; Feuerwerker; Cerqueira, 2014, p. 74).
Além disso, destacamos que para Merhy (1999), todo processo de trabalho em saúde produz atos de saúde. Então, produzir procedimentos é também produzir atos de saúde, o que não garante que se produza cuidado no sentido 'cuidador'.

Assim, considerando que a produção do cuidado se dá sempre em relação, Rolnik (2016) afirma que a forma do sujeito agir diante do cotidiano é singular e, assim, múltiplo, "pois temos sempre tantos mundos quantos são os que o habitam". A autora afirma, ainda, que o território existencial habita o sujeito de forma que, independente do serviço em que estiver atuando, irá operar o cuidado de uma forma e não de outra. Neste contexto, nem sempre o processo de trabalho permite a produção de saúde, pois dificulta os encontros genuínos e não auxilia na promoção de graus de autonomia no modo de andar na vida do usuário (Merhy, 1999). Assim, para produção do cuidado, deve-se ter como princípio a construção da autonomia e seu fortalecimento no decorrer do processo saúde-doença.

Para diferentes autores, a autonomia adquire vários significados. Neste artigo, amplia-se o conceito para além de uma independência absoluta. Trata-se a autonomia como condição necessária para a saúde. 
A partir da noção de complexidade, Morin (1996) questiona o conceito de autonomia como liberdade e defende que a autonomia é estritamente ligada a noção de dependência. $\mathrm{O}$ autor evidencia que a autonomia não se trata de uma liberdade absoluta, emancipada de qualquer dependência, mas defende que "a autonomia depende de seu meio ambiente, seja ele biológico, cultural ou social. Assim, só podemos ser autônomos a partir de uma dependência original em relação à cultura, em relação a uma língua, em relação a um saber" (Morin, 2003, p. 118). Para Morin, a autonomia implica na dependência com o mundo externo (seja a família, a escola, o trabalho, as relações interpessoais). Neste ponto, considera-se que a autonomia não se constitui como valor absoluto, de modo que implica certo grau de dependência e, portanto, maiores ganhos de autonomia implicam melhores condições do indivíduo se auto-organizar.

Merhy (1999) afirma que o cuidado pode e deve implicar ganhos de autonomia para o paciente. Até porque a saúde é concebida como a capacidade de gerar mais vida, assim como a capacidade de produzir redes que produzem mais vida. Desta forma, essas redes de dependência fortalecem a autonomia (Morin, 1996) e implicam diretamente na produção do cuidado.

Neste sentido, questiona-se, então, como os serviços de saúde podem contribuir na produção de autonomia do usuário? Segundo Merhy (2007b, p. 123), pode haver um cuidado que seja cuidador, porém, uma das implicações mais sérias do atual modelo hegemônico é a perda da dimensão cuidadora. O autor afirma que a 'morte' dessa dimensão tem possibilitado a construção de "modelos de atenção irresponsáveis perante a vida dos cidadãos".

Assim, a partir de tais reflexões sobre o processo de trabalho e sobre a produção do cuidado em um serviço de saúde, este estudo analisa os desafios na produção do cuidado em um CAPSad, enfatizando que o CAPSad está sujeito a diversidade de políticas que orientam suas práticas, já que em outro artigo* se assinala que este serviço opera segundo duas diretrizes contraditórias entre si, a Política Nacional sobre Drogas, com foco na repressão, na ação da justiça e da polícia, e a Política de Atenção Integral aos Usuários de Álcool e outras Drogas (PAIUAD), do Ministério da Saúde, com foco na redução de danos e na valorização da singularidade do sujeito. Além disso, afirma-se que no município em que se situa o serviço estudado, as divergências entre as diretrizes se 
verificam inclusive entre os níveis federal e municipal, já que em oposição à PAIUAD, o município realiza estratégias com foco no amedrontamento, na repressão e na ação policial (Wandekoken; Dalbello-Araujo 2015).

No CAPSad estudado, as dimensões macro e micropolíticas implicam efeitos subjetivos vivenciados pelos trabalhadores e que interferem na produção do cuidado. Em relação às dimensões macropolíticas, destacam-se: condições de trabalho precárias (devido à estrutura do serviço, baixos salários e rede de atenção inexistente) e sobrecarga (devido à falta de profissionais); e entre as dimensões micropolíticas encontramse a falta de reconhecimento (devido à omissão da gerência e à ausência de normas) e sobrecarga (devido aos conflitos nas divisões de tarefas) (Wandekoken; Dalbello-Araujo 2015).

Frente a estas questões, este artigo analisa os desafios na produção do cuidado em um CAPSad, em busca de agir consonante às políticas que orientam o serviço. Debruça-se também em analisar as dimensões macro e micropolíticas que permeiam esta prática e elucida estratégias do processo de trabalho que são vivenciados pelos trabalhadores.
*Wandekoken KD, Dalbello-Araujo M. Trabalho no Centro de Atenção Psicossocial Álcool e Drogas e as políticas públicas: que caminho seguir? Trab. educ. saúde. 2015; 13 Supl. 1: 15775 .

\section{Método}

Foi realizada uma pesquisa

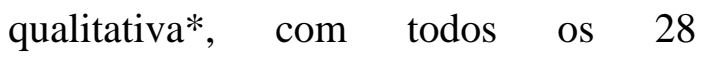
trabalhadores do CAPSad, incluindo médicos, enfermeiros, psicólogos, assistentes administrativos, motoristas, recepcionistas, vigilantes, auxiliares de serviços gerais, farmacêuticos, educadores físicos, terapeutas ocupacionais, gerentes, técnicos de Enfermagem e assistentes sociais. Dessa forma, buscou-se adotar uma perspectiva ampliada da categoria, pois entende-se que todos, e não só aqueles que detém conhecimentos técnicos da área da saúde, são capazes de intervir na cadeia produtiva do cuidado em saúde (Merhy; Feuerwerker; Cerqueira, 2014).

A produção de dados foi realizada entre os meses de janeiro e abril do ano de 2014, a partir de três técnicas: 80 horas de observação do cotidiano do serviço, incluindo as reuniões de equipe e as assembleias de usuários; 1 sessão de entrevista coletiva com a participação de dez profissionais e 13 entrevistas individuais, em profundidade. A técnica de observação foi importante para identificar os 
comportamentos não intencionais e reações inconscientes, e, dessa forma, explorar questões que as pessoas não se sentem à vontade para discutir. A entrevista coletiva, conforme explica Dalbello-Araujo (2008), consiste em uma técnica usada quando se pretende facilitar o acesso aos diferentes pontos de vista entre os participantes. Já as entrevistas em profundidade foram realizadas a partir da questão disparadora: 'o que você acha de trabalhar aqui?'.

Todos os dados foram anotados e transcritos em um diário de campo, que, junto com as transcrições das entrevistas, foram submetidos à Análise Temática, derivada da Análise de Conteúdo, desenvolvida por Bardin (2011). A Análise Temática está ligada à noção de tema, que pode ser graficamente apresentado por meio de uma palavra, uma frase, um resumo (Bardin, 2011).

Os participantes assinaram de forma voluntária o Termo de Consentimento Livre e Esclarecido, no qual tiveram a garantia do sigilo de identidade e das informações prestadas. Assim, as identificações dos trechos obedecem a três formatos: a palavra 'Trabalhador' ou 'Trabalhador em roda', quando se refere aos trabalhadores em falas individuais ou coletivas, respectivamente; 'Assembleia dos usuários', quando o trecho teve relação com a fala de algum usuário no período da observação; e a palavra 'Diário de campo' quando se trata do registro de observação do cotidiano realizado pelos pesquisadores.

* Foram atendidas as prerrogativas da Resolução n. 466/12 do Conselho Nacional de Saúde, sendo aprovado sob o número de registro $\mathrm{n}$. 16771113000005060 pelo Comitê de Ética em Pesquisa da Universidade Federal do Espírito Santo.

\section{Resultados e Discussão}

Para análise e discussão dos resultados, foram criadas três categorias que apresentam as diferentes modalidades em que o cuidado é realizado: cuidado centrado no ato prescritivo (baseado em procedimentos e/ou prescrições), cuidado pouco relacional e cuidado acolhedor. Não obstante, o fato de estas categorias poderem se interrelacionar, foram selecionados alguns trechos do diário de campo e/ou entrevistas que ilustram cada uma destas categorias e que serão apresentados ao longo da discussão.

\section{Cuidado centrado no ato prescritivo:}

Para Merhy (2007), produzir cuidado a partir do trabalho em saúde depende da construção de aspectos relacionais, seja entre gestores e trabalhadores, entre trabalhadores $\mathrm{e}$ 
usuários. No entanto, a relação entre estes últimos, por exemplo, pode evidenciar um processo engessado em procedimentos, de forma que o usuário é tido como objeto, sem saber sobre seu próprio corpo e negado ou desqualificado, devido suposto menor valor científico.

Isto pode ser observado na categoria cuidado centrado no ato prescritivo, exemplificada a partir da fala de um usuário do CAPSad: "Tem um certo trabalhador que nem olha na cara da gente para prescrever algo... Um dia cheguei lá para pedir uma receita porque estava com dificuldade para dormir, X [o trabalhador] prescreveu e entregou a receita sem nem ao menos questionar se eu usava algum remédio ou qualquer outro assunto [...] É preciso que $X$ [o trabalhador] nos trate com carinho, nós somos pessoas, e a atitude dele não é coerente com os demais do CAPSad" (Assembleia de usuários).

Diante desta fala, aponta-se que, para Merhy (1998), os usuários, muitas vezes, se sentem inseguros, desprotegidos e desrespeitados, diante da falta de interesse do profissional da saúde em relação ao seu problema.

Assim, por mais que o processo de prescrição de uma receita produza algum ato de saúde, não se pode afirmar que ocorreu produção de saúde, já que não houve nenhum impacto em ganhos de autonomia por parte do usuário, na sua forma de andar na vida. Até porque esta forma de se relacionar com $o$ usuário é 'procedimento centrada' e não 'usuário centrada', conforme Merhy (1998), e se esgota na produção de paciente diagnosticado e medicado, sem que se tenham satisfeitos seus direitos como usuário. Como exemplo, aponta-se o caso de um paciente que se desloca ao hospital devido aos sintomas de gripe e é apenas medicado, sem que tenha ocorrido nenhum ato relacional neste encontro que produza maior autonomia por parte deste paciente. Assim, com base em Merhy, afirma-se que o ato do trabalhador pode sim ser um ato de saúde, sem que tenha produzido saúde. Até porque, segundo o autor, produzir saúde vai além de atos prescritivos, tem a ver com a construção de maior autonomia.

Segundo Ceccim e Merhy (2009, p. 533), a centralidade no usuário é "a centralidade no encontro, no contato com a alteridade", de forma que o cuidado passa a ser um campo singular da produção da saúde.

Para tanto, se observa que, em algumas circunstâncias, para atender a demanda do usuário, o profissional usa, exclusivamente, de prescrições e 
medicações, de forma que seu trabalho é centrado em atos prescritivos.

No entanto, pelo depoimento do usuário, ao afirmar que é preciso que o profissional lhes trate com carinho, pois são pessoas, ele está, de fato, sugerindo que o processo terapêutico seja mais relacional. Ou seja, que mesmo utilizando-se de recursos instrumentais necessários (como são as prescrições), haja o interesse pelo usuário, como pessoa que também possui uma história e uma subjetividade.

Neste sentido, Merhy (2007b) defende que deve haver uma relação adequada entre as tecnologias dura, levedura e leve, de forma que só assim se pode pensar em produção de cuidado com maior defesa da vida do usuário e na produção de maior autonomia.

Fato é que o cuidado centrado no ato prescritivo observado neste CAPSad compromete toda uma rede assistencial. Franco e Merhy (2013) afirmam que não existe autossuficiência na saúde, de forma que nenhum trabalhador pode, sozinho, afirmar que consegue uma resolutividade satisfatória frente às necessidades dos usuários. Assim, observa-se que o processo produtivo é altamente relacional e por vezes pode até gerar tensões e conflitos como pudemos observar: "No último grupo, o $\quad X$ [trabalhador] destratou o paciente. Em seguida, revoltado o usuário foi ao grupo e eu não tive como fazer o grupo, porque o usuário estava muito descontrolado, dizendo que queria voar no pescoço de $X$ [trabalhador] que o destratou (Trabalhador). "Eu não confio de deixar os pacientes sozinhos com $X$ [trabalhador]... eu entro junto na consulta. Além disso, sabemos que $X$ [trabalhador] não tem empatia com os pacientes, não tem vínculo... precisa que eu vá junto para discutir o caso. Nesses casos eu tenho que deixar de atender, de fazer meu trabalho, para ir acompanhar a consulta, o que é desgastante" (Trabalhador). "Prejudica muito a gente, porque tem que escutar pacientes o tempo todo reclamando no nosso ouvido" (Trabalhadores em roda).

Nestes depoimentos, observa-se que há desgaste e sentimento de incapacidade de agir frente às condutas de um único trabalhador, o que compromete toda a produção de cuidado. Neste ponto, questiona-se sobre o que os trabalhadores têm feito para alterar esta situação, e observa-se, nas falas abaixo, que os relatos da 'incapacidade de agir' são vários: "Nada é feito, a gerência não toma providências... as reclamações nem chegam ao ouvido dela! [gestão]" (Trabalhadores em roda). "Não vou me manifestar sobre o caso, porque, como 
sempre, nada vai ser feito" (Assembleia de usuários). "Os usuários sempre reclamaram, e nada acontece, nada muda, ninguém faz nada... quer dizer, quem deveria fazer não faz nada, né!" (Trabalhador). "Nós orientamos o usuário a procurar a ouvidoria, o Ministério público... Oriento o usuário a falar com a gerência" (Trabalhadores em roda).

Como se observa, os trabalhadores e usuários não sabem o que fazer e apenas atribuem a responsabilidade à gestão. Além disso, ressalta-se trechos em que alguns trabalhadores parecem não se importar com estas situações: "Estou muito ocupado com demandas pessoais... posso até tentar conversar com esse X [trabalhador] um dia, mas já fiz isso uma vez e não resolveu" (Trabalhador). "O SUS é assim mesmo, os trabalhadores do SUS são assim... Estou pensando, inclusive, em trocar de cardiologista (neste momento ri), pois ele é grosso. X [trabalhador] é assim, não tem jeito... os usuários precisam se abrir nos grupos e desabafar" (Trabalhador). "O jeito são vocês se conformarem [os usuários], já que pelo menos o trabalhador ainda não errou nenhuma receita. Já tem várias reclamações sobre esse trabalhador... já conversamos com ele, mas nada se resolveu" (Trabalhador).

Frente a estas falas, considera-se que há, por parte de alguns trabalhadores, e não só do trabalhador que produz o cuidado centrado em atos prescritivos, uma postura de banalização da dor e do sofrimento alheio, além de uma clara desvalorização da vida. Percebe-se, ainda, uma descrença no Sistema Único de Saúde (SUS) e a conformação de que as situações são desta forma, o que, segundo os trabalhadores, já seria o suficiente.

Ressalta-se, ainda, a fala "pelo menos o trabalhador ainda não errou nenhuma receita", pois aponta uma produção do cuidado que valoriza, sobremaneira, os atos prescritivos. O que se observa, são saberes ditos onipotentes em relação aos demais e, no entanto, nem por isso mais eficazes em satisfazer as necessidades dos usuários. Até porque não considera que o trabalho em saúde é baseado no encontro entre o trabalhador e o usuário e que, diante disto, as tecnologias mais relacionais e $\mathrm{o}$ envolvimento afetivo são imprescindíveis. Frente a estas questões, aponta-se mais uma categoria: 


\section{Cuidado pouco relacional}

Seguem alguns depoimentos que exemplificam esta categoria: " $X$ [trabalhador] chega, não cumprimenta ninguém, fica na sala, atende, vai embora e ninguém vê!!" (Trabalhador). "[...] aí o usuário não cria vínculo com $X$ [trabalhador], não expressa o que ele sente..". "O tratamento do usuário é prejudicado, pois ele tem medo de $X$ [trabalhador]... não volta na consulta". "Falta conhecer o paciente, o 'olho no olho'" (Trabalhadores em roda). "Eu não gosto de trabalhar no CAPSad, porque não gosto da assistência... prefiro trabalhar na administração, gestão, elaborando cursos" (Trabalhador). "Eu não coordeno grupo porque não suporto ter que ouvir e não poder falar o que eu quero! Eu não dou conta de estar num grupo, de pensar de um jeito e agir de outro" (Trabalhador). "Tenho medo de X [trabalhador], do jeito que ele fala comigo... (Assembleia de usuários).

Merhy e Franco (2013, p. 124) apontam que na produção do cuidado está implicada a dimensão humana e subjetiva de cada um, e, assim, deve-se considerar que os trabalhadores são portadores de subjetividade e que tal opera no cotidiano de trabalho. Assim, o modo como o trabalhador compreende a vida do outro, seus valores e a forma como ele lida com os demais membros da equipe, sua adesão à diretriz do CAPSad e a singularidade de cada trabalhador, altera a forma como trabalha.

Para tanto, o fato de, por exemplo, não estimar o trabalho na assistência ou não suportar ter que ouvir os usuários, só pode implicar um cuidado pouco acolhedor e nada relacional, o que compromete toda uma produção de cuidado. Neste ponto, Merhy (2007b, p. 138) afirma que ao questionar o usuário sobre o que ele espera dos atos de saúde, a resposta é semelhante e tem a ver com o envolvimento do trabalhador com suas necessidades, mais do que com procedimentos, "serem pessoas reais, tratando de pessoas reais".

Por outro lado, impressiona o depoimento de um trabalhador comparar o atendimento ao usuário à atividade de carimbar papel: "[...] eu fico imaginando assim uma pessoa que está numa repartição, só carimbando papel, né... e aí, às vezes, atender alguns usuários é como se você, toda a semana, você tivesse carimbando um papel, entende? (risos) Que... assim... tem gente que não dá um retorno... o papel você ainda encaminha para outro setor, $e$ o usuário? Às vezes ele vai e volta, vai e 
volta, é igual um processo que não tem solução! Não tem jurisprudência... porque depende da vontade pessoal, nós estamos lidando com pessoas" (Trabalhador).

Diante desta comparação, só cabe afirmar, mais uma vez, que a simplificação das demandas de saúde, de forma a não produzir atos cuidadores mais relacionais, leva a constatação de que estas práticas só podem produzir baixa resolutividade e, assim, menor eficácia do serviço de saúde.

Neste ponto, Merhy e Franco (2013, p. 127) afirmam que a produção de acolhimento, de vínculo e de autonomização do usuário são indicadores da eficácia e da efetividade de um serviço de saúde.

Para tanto, é preciso que o trabalhador reconheça no usuário alguém portador de desejos e necessidades, alguém que possui valores e potências. Questões que precisam ser consideradas na produção do cuidado. Vislumbrando isto, o trabalhador afeta e se deixa ser afetado, de forma a favorecer que o usuário conduza sua própria vida.

Assim, compreende-se que há um intenso processo micropolítico na produção do cuidado em saúde, implicado nos encontros singulares das ações cuidadoras (Merhy, 2007). Até porque as ações cuidadoras por meio das tecnologias relacionais não são domínio apenas dos profissionais da saúde, mas de todos que atuam nessa área e dos usuários e seus familiares (Merhy, 2007). Frente a estas questões, segue mais uma categoria:

\section{Cuidado acolhedor:}

Produzir atos de saúde a partir de uma dimensão cuidadora é tarefa de todos os trabalhadores do CAPSad, até porque todos podem e devem acolher, escutar, olhar, se interessar e contribuir para que relações de confiança e empatia sejam produzidas. Estas atitudes foram percebidas no decorrer do campo: $O$ trabalhador sentou ao lado de uma usuária que havia sido atendida $e$ conversou durante algum tempo. Depois, a usuária agradeceu muito a conversa e se despediu (Diário de campo). Logo que o usuário entrou no CAPSad, o trabalhador veio $e$ o cumprimentou. Pareceu gostar de vê-lo. Sentou ao seu lado e conversaram durante algum tempo sobre como as 'coisas andavam'. $O$ trabalhador ainda interessado perguntou se ele estava bem. $X$ mencionou que havia 'caído', uma 'queda' grande, mas que depois se levantou, ficou internado e pretendia voltar ao CAPSad (Diário de campo). Vi que o trabalhador conversava bastante 
com os usuários que estavam na recepção, perguntando sobre como eles estavam, se estavam bem ou não, além de brincar com eles sobre o fato de hoje ser o dia da mentira (Diário de campo).

Como se vê, é fundamental que os trabalhadores estabeleçam um bom contato com o usuário e isso implica colocá-lo em uma posição ativa no processo de saúde. Até porque, nestes encontros cuidadores, pode-se contribuir para a construção da autonomia do usuário.

Merhy e Franco (2013b, p. 142) afirmam que em situações como estas, o processo de trabalho está centrado em formas de produção de cuidado mais relacionais ao considerar que no encontro o usuário é também sujeito produtor de cuidado.

Franco e Merhy (2013) apontam, ainda, que o trabalho em saúde se processa em uma rede de relações, em que não está excluído nenhum trabalhador, nem ao menos os trabalhadores das áreas de 'apoio', como os vigias e auxiliares de limpeza.

Assim, segundo Merhy (2007), é o cuidado (e não a atividade clínica) que é a alma dos serviços de saúde e a estratégia para a defesa da vida. Além disso, Ceccim e Merhy (2009) ressaltam que o encontro é da ordem micropolítica, de forma que tem seus mistérios e riquezas frente aos processos relacionais implicados.

Destaca-se, neste ponto, as falas de trabalhadores que acreditam que o CAPSad não deve estar vinculado a determinadas abordagens realizadas junto às pessoas que estão em situação de rua, pois acreditam que o serviço é diferente: "[...] teve uma época em que eles [a prefeitura] estavam fazendo muita ação na rua, e era ação realmente de recolher... a gente sabe que tinha uma pressão policial envolvida e aí a gente bancou não entrar nisso " (Trabalhador). Haviam duas caçambas grandes e um carro pipa. As caçambas foram usadas para jogar os pertences dos moradores de rua e o carro pipa foi usado para jogar água no local, evitando assim que eles retornem. Havia policiais, pessoas que atuam na abordagem de rua, vários guardas municipais, e apenas três pessoas em situação de rua. Observamos apenas de longe, já que o trabalhador afirmou que não gostaria que os moradores o vissem para que o CAPSad não fosse associado a estas abordagens (Diário de campo). "A ação durará até sexta-feira e acontecerá na parte da manhã e da tarde... é melhor ficarmos de longe para que eles não vejam a gente e não associem o CAPSad a essas 
abordagens... Toda a equipe do CAPSad acredita que essas abordagens são contrárias ao que nós fazemos e por mais que a prefeitura tenha solicitado o apoio do serviço, nós não aceitamos! Eu estive na reunião, no gabinete do prefeito, e lá disseram que esta ação é para dar uma resposta à reportagem que foi veiculada na mídia alguns dias atrás. Eles usaram palavras como higienização das ruas, disseram que era para retirar os moradores, ameaçá-los e expulsá-los" (Trabalhador).

Como se observa, os trabalhadores optaram por exercer uma produção do cuidado a partir do vínculo e do acolhimento, de forma que as abordagens com base na ação policial e na higienização das ruas são, de fato, opostas ao que os trabalhadores do CAPSad e a PAIUAD propõem. Com base nestes depoimentos, é preciso enfatizar a afirmação de Merhy e Franco, (2013) quando mencionam que na produção do cuidado, que ocorre sempre em ato, o trabalhador possui muita liberdade de operar, de forma que no trabalho em saúde há certo autogoverno dos trabalhadores que lhe confere liberdade no cotidiano de trabalho.

Do mesmo modo, em outro momento, um trabalhador apontou que a atividade de internação compulsória realizada por alguns trabalhadores do CAPSad, após orientação da prefeitura, não condiz com as demais atividades do serviço: "A internação compulsória tem uma lógica totalmente diferente do CAPSad... o CAPSad é antimanicomial e está de acordo com os princípios da Reforma Psiquiátrica! É vínculo, é acolhimento, a aposta do CAPSad é a reforma psiquiátrica! Então é difícil, porque a internação compulsória é outra ideologia... então somos capturados por isso aí! Mas isso não impede que, nessa dureza, porque é uma ação dura, nós levemos a nossa leveza, a nossa forma fluida, para esse contato com o usuário... Como eu tenho certeza que quem vai lá, mesmo que não entenda, não questione, mas procura fazer, de uma outra forma... ao invés de mandar ele ir, o convida, sugere, faz de outro jeito... lá é polícia... nós não somos militarizados. Quer dizer, somos militarizados, no amor, no acolhimento, no direito da pessoa decidir se quer ou não, na sua loucura, na vida!"(Trabalhador).

Ao afirmar "somos militarizados, no amor, no acolhimento" o trabalhador expressa uma aposta no acolhimento e no vínculo como dispositivos de mudança. 


\section{Conclusão}

Tendo em vista a análise dos desafios da produção do cuidado em um CAPSad e considerando que a produção do cuidado em saúde se dá sempre em relação, constata-se que, neste serviço, há comprometimento de sua efetividade. Foram observados três modos de cuidar: 1. Cuidado centrado no ato prescritivo; 2. Cuidado pouco relacional; 3 . Cuidado acolhedor. Ou seja, em algumas situações, a produção do cuidado é realizada por meio de atos prescritivos ou pouco relacionais, o que não contribui na produção de autonomia do usuário.

$\mathrm{Na}$ prática, as ações relacionadas à saúde têm perdido sua dimensão cuidadora, o que compromete toda sua eficácia e eficiência. Enfatiza-se, neste ponto, que produzir atos de saúde a partir de um cuidado acolhedor é tarefa de todos os profissionais do CAPSad e que estes devem reconhecer no usuário alguém portador de desejos e necessidades, que possui valores e potências. Entretanto, nas condições em que o trabalho é realizado, no local estudado, este aspecto fica altamente comprometido.

Foram evidenciadas limitações do estudo, uma vez que, em decorrência da metodologia empregada, não é possível a generalização dos resultados para os demais CAPS do sistema de saúde.

Não obstante, há carência de estudos que apontam desafios na produção do cuidado em serviços de saúde mental, fato este que procurou-se minimizar. Para tanto, a pesquisa em questão, atinge o objetivo proposto, uma vez que contribui em direção a estas discussões e enfatiza que, no trabalho em saúde, há sempre certo autogoverno dos trabalhadores, constatando que, para que haja mudanças na produção do cuidado, há que se atentar para o agir dos trabalhadores de saúde, oferecendo espaços coletivos de fala para que estes possam discutir e refletir sobre o que tem sido produzido no transcurso de seu trabalho. 


\section{Referências}

1. Bardin L. Análise de conteúdo. São Paulo: Edições 70; 2011.

2. Ceccim RB, Merhy E.E. Intense micropolitical and pedagogical action: humanizationbetween ties and perspectives. Interface Comun. Saúde Educ. 2009; 13 Supl 1:531-42

3. Dalbello-Araujo M. Comunidade ampliada de pesquisa. In: Rosa EM, Souza L, Velar L, organizadores. Psicologia Social: temas em debate. Vitória: GM. Editora-ABRAPSO-ES; 2008. p. 109-26.

4. Deleuze G, Guattari F. Mil Platôs: capitalismo e esquizofrenia. v. 3. Rio de Janeiro: Ed. 34; 2012.

5. Franco TB. Prefácio. In: Franco TB, Andrade CS, Ferreira VSC, organizadores. A produção subjetiva do cuidado: cartografias da Estratégia Saúde da Família. São Paulo: Hucitec; 2011.

6. Franco $\mathrm{T}$ et al. A produção subjetiva da estratégia da saúde da família. In: Franco T, Andrade CS, Ferreira VSC, organizadores. A produção subjetiva do cuidado: cartografias da estratégia saúde da família. São Paulo: Hucitec; 2011. p. 19-44.

7. Franco TB, Merhy EE. Trabalho, produção do cuidado e subjetividade em saúde. Hucitec Editora; 2013.

8. Merhy EE. A perda da dimensão cuidadora na produção da saúde: uma discussão do modelo assistencial e da intervenção no seu modo de trabalhar a assistência. In: Campos CR, organizador. Sistema Único de Saúde em Belo Horizonte: Reescrevendo o público. São Paulo: Xamã Editora; 1998. p. 103-20.

9. Merhy EE. O ato de governar as tensões constitutivas do agir em saúde como desafio permanente de algumas estratégias gerenciais. Ciênc. saúde coletiva. 1999; 4 (2): 305-14.

10. Merhy EE. Em busca do tempo perdido: a micropolítica do trabalho vivo em saúde. In: Merhy EE, Onocko R, organizadores. Agir em saúde: um desafio para o público. 3 ed. São Paulo: Hucitec; 2007. p. 71-112.

11. Merhy EE . Saúde: a cartografia do trabalho vivo. São Paulo: HUCITEC; 2007b.

12. Merhy EE, Feuerwerker LCM, Cerqueira P. Da Repetição à Diferença: construindo sentidos com o outro no mundo do cuidado. In: Silva Jr AG, Ramos VC, Damasceno V, organizadores. Semiótica, Afecção e Cuidado em Saúde. São Paulo: Hucitec; 2014. p. 60-75.

13. Guattari F, Rolnik S. Micropolítica: cartografias do desejo. $12^{\mathrm{a}}$ ed. Petrópolis: Vozes; 2011.

14. Merhy EE, Franco TB. Reestruturação produtiva e a transição tecnológica na saúde: debate necessário para a compreensão do processo de 'financeirização' do mercado na saúde. In: Franco TB, Merhy EE, organizadores. Trabalho, produção do cuidado e subjetividade em saúde. São Paulo: Hucitec Editora; 2013. p. 85-111.

15. Merhy EE, Franco TB. Por uma composição técnica do trabalho centrada no campo relacional e nas tecnologias leves. In: Franco TB, Merhy EE, organizadores. Trabalho, produção do cuidado e subjetividade em saúde. São Paulo: Hucitec Editora; 2013. p. 112- 21.

16. Morin E. A Noção de Sujeito. In: Schnitman DF, organizador. Novos Paradigmas, Cultura e Subjetividade. Artes Médicas; 1996. 
17. Morin E. A cabeça bem feita: repensar a reforma, reformar o pensamento. Tradução de Eloá Jacobina. $8^{\mathrm{a}}$ ed. Rio de Janeiro: Bertrand Brasil; 2003.

18. Rolnik S. Cartografia Sentimental. 2 ed. Porto Alegre: Ed. UFRGS; 2016.

19. Wandekoken KD, Dalbello-Araujo $\mathrm{M}$. Trabalho no Centro de Atenção Psicossocial Álcool e Drogas e as políticas públicas: que caminho seguir? Trab. educ. saúde. 2015; 13 Supl. 1: 15775.

\section{Participação dos autores:}

WANDEKOKEN, KD trabalhou na concepção teórica, coleta de dados, análise de dados, elaboração e redação final do texto.

ARAUJO, MD trabalhou na concepção teórica, elaboração, análise de dados e redação final do texto.

BORGES, LH trabalhou na concepção teórica, elaboração, análise de dados e redação final do texto.

Recebido: 26.06.2017

Revisado: 11.07.2017

Aprovado: 23.07.2018 